\title{
Comparative Study on Anxiety between Student Players of Different Ball Games in 2013 National Ethiopian Universities Sports Competition
}

\author{
Kesatie Legesse* \\ Department of Sports Science, Mekelle University, P.O.Box 231, Mekelle, Ethiopia \\ (*kesatielegesse@yahoo.com).
}

\begin{abstract}
Anxiety is made up of mental and physiological components. Researchers have indicated that there is a relationship between anxiety and performance. Present paper tries to investigate the level of anxiety between student players of different games, football volleyball and basketball representing different universities at intercollegiate games held in Haromia University in 2013. A survey was carried out on one hundred and eighty two student players $(n=182)$ out of 300 participated, representing various universities and from different parts of Ethiopia. Only male players aged between 18-25 years were selected for the study. Maximum effort and meticulous care was taken while recording the measurements with precision and accuracy. Sports Competitive Anxiety Test (SCAT) was used to measure anxiety level among the football and other players. To compare anxiety between football, volleyball and basketball one way analysis of variance (ANOVA) was employed setting the level of significance at 0.05 . The results revealed that anxiety level showed significant difference for the three ball games. The anxiety level for players of football was found to be highest among others $(\mathrm{F}=31.97, \mathrm{p}<0.05)$. This implies that football game by its very nature is anxiety -inducing. This necessitates the need for anxiety alleviation intervention before the tournament for successful performance and achievement in the competition.
\end{abstract}

Keywords: Anxiety, Football, Volleyball, Basketball, Ethiopia.

\section{INTRODUCTION}

Many studies show that the psychology component anxiety interferes with the performance of an athlete. If, anxiety is too much, it can hamper or negatively affect the performance and achievement in games including sport games (Lazarus, 2009). In this vein, performance and a high degree of achievement are true reflexes of the wonderful world of competition that an anxiety is an important component that needs to be addressed properly. Nothing could have been higher, faster and further if, there had been no competition in sports. Whenever there is competition, players or actors start to think or bother about the tournament or competition on account of losing or hitting the target and this causes them partly to be anxious and this becomes very serious if they game involves football as football is the most popular and have the most audience/ followers all over the globe. At the same time, the modern sports which provide fame 
besides earning benefits have compelled athletes to take sports competition seriously and as a full time business.

Different authors have studied this subject and tried to identify the factors that influence sport performance of players. Some of the factors are strength, resource, orientation among others. Layel (2007) considered anxiety as an important factor and tried to provide ranking to anxiety factor. According to him, it is an important influential factor and for that matter it has been said that anxiety is one of the important psychological variables in sports and it is also needed to achieve high level of competition. Without knowledge of this variable athletes cannot give best in the competitions. Similar studies by Kornspan (2007); Grange and Kerr (2010); Singh et al. (2012); Najmuddin and Shahnawaz (2014); Suman and Kuntal (2014); Maibam and Nongdren (2015); Ratnesh and Inder (2016) have also demonstrated the impact of psychological factors on sports performance.

In essence, anxiety is a psychological and physical state characterized by somatic, emotional, cognitive and behavioral components. The root meaning of the word anxiety is to vex or trouble; in either the absence or presence of psychological stress, anxiety can create feelings of fear, worry, uneasiness and dread. Anxiety is considered to be a normal reaction to a stressor. It may help a person to deal with a difficult situation by prompting one to cope with it. When anxiety becomes excessive, it may fall under the classification of an anxiety disorder. Physical effects of anxiety may include heart palpitation, muscles weakness and tension, fatigue, nausea, chest pain, shortness of breath, stomach ache/ head ache and immune and digestive system function are inhabited (the fight or flight response). External signs of anxiety may include pale skin, sweating, trembling and papillary dilation. Someone who has anxiety might also experience it as a sense of dread or panic (Lazarus, 2009, pp, 102). The level of anxiety differs from individual to individual, team to team but depends on the training, diet, climate, support etc.

Thus, anxiety is not a stable trait among players before, during and after the competition that requires a precise measurement to understand and determine its level. All the players may have different anxiety level accordingly, and such no study or investigation has been done particularly in Ethiopia on the Government Universities sport competitions hosted by different universities every year. In this backdrop, the present paper tries to understand the before game anxiety level of players and its effect on the performance in three different games during Ethiopian universities intercollegiate competitions. The study thus is planned to investigate and compare 
the level of anxiety among foot ball, volley ball and basketball teams participating in these Ethiopian government universities. And pin point intervention programs as to how to alleviate the anxiety level among football players before commencing the competition, and address the question why football competition is among highest anxiety evoking competitions in the intercollegiate games especially before the onset of the tournament among its players.

\section{METHODOLOGY}

\subsection{Sampling}

The samples are drawn from the population of student players representing different universities participating in the National Ethiopian Universities Sports Competitions (NEUSC) held in Haromia University in 2013-14. Players ranging in age from 18-25 years from football, volleyball and basketball were chosen. The subjects (samples) were selected by using purposive sampling technique. In total, eighteen university teams have participated in ball games competition and 182 players form football were selected for the present study out of the 300 target population from football, volleyball and basketball teams.

\subsection{Instrumentation}

\begin{tabular}{|lll|}
\hline Variable & Tools used & Criterion measure \\
\hline Sports Competitive Anxiety & $\begin{array}{l}\text { Rainer marten, sports competitive } \\
\text { anxiety test (SCAT, 1990) }\end{array}$ & Points \\
\hline
\end{tabular}

\subsection{Collection of data}

After consulting relevant literatures, a standard questionnaire is developed to obtain different data. The researcher used mainly the study sport competitive anxiety test (SCAT) prepared by Rainer Marten (1990) to collect the relevant data from all the samples of the study. This is used because it is pilot tested and found to have a good reliability index.

\subsection{Inventory and Procedure}

The inventory was first administered in groups, 20 subjects per group. The subjects were seated comfortably and as far as possible prevented not to have a chance to talk to other players or glance at their responses for confidentiality purpose. By explaining the purpose of the test the author tried to get full co-operation from the student- players. The inventory is self administering. All the instructions were printed on the front cover page of the inventory and it was also read out to some students and explained in detail. The subjects were encouraged to give 
their own and true opinion and assured its confidentiality. After the test is over the test material of every subject was collected carefully.

The scoring was done with the help of scoring key given in the manual itself as a guide. Each statement in the questionnaire has 3 alternatives choices (always, sometimes and hardly ever) and was clearly indicated in the manual. The subjects were asked to choose any one as applicable to him/her. Score points 1, 2, 3 were awarded for the choices. The sum of the score points (raw score) was then obtained as per his/her ratings accordingly.

\subsubsection{Procedure}

It was made sure that in the eve of the competition, the players remain in a quite environment, not taken any caffeine, had enough sleep and are in a good emotional state of mind. They were also checked for any congenital problems and general medical condition by the health personnel. In addition, the diet that they have to take was also checked for content and nutritional value. The weather condition was also noted as sunny and gently windy environment that did not had any serious influence on their overall performance.

\subsection{Reliability and Validity}

The inventory used is a kind of checklist adapted after making sure that it is valid and reliable measure at the face value. Except some modifications made at the language level, it was adapted as it is. The questionnaire's reliability was found to be about 0.88 . This reliability coefficient makes the test or questionnaire to be highly consistent and reliable for using in this new setting or environment.

\subsection{Statistics}

The data was processed using descriptive statistical analysis. The data obtained from the given responses in the questionnaire are rated according to the key and analyzed using one way analysis of variance (ANOVA) test for each item and further LSD post hoc test was used. The level of significance was set at 0.05 .

\section{RESULTS}

To observe the difference in anxiety between football, volleyball and basketball players of different universities participating in National Ethiopian Universities Sports Competitions the result of one way analysis of variance (ANOVA) has been used and presented below. 
Rainer and Marten (1980) anxiety inventory was used to assess and measure the level of anxiety before the game or scheduled matches in the tournament. The data was gathered from the questionnaire tool, before the players actually entered the competition period during the Ethiopian Public University Sport Festivals (EPUSF). Based on the data gathered and the statistical method employed the following results were obtained.

Table 1. Descriptive analysis of data on anxiety for different football, basketball and volleyball players participated in National Ethiopian Universities Sports Competitions (NEUSC), Haromia University (2013-14).

\begin{tabular}{|llllll|}
\hline Group & $\boldsymbol{N}$ & Mean & Std. Deviation & Minimum & Maximum \\
\hline Football & 100 & 29.917 & 5.103 & 20.00 & 41.00 \\
\hline Basketball & 100 & 26.400 & 2.799 & 21.00 & 21.00 \\
\hline Volleyball & 100 & 24.683 & 2.487 & 21.00 & 30.00 \\
\hline
\end{tabular}

The descriptive statistics as presented in table 1 reveal that the mean and standard deviation for football, basketball and volleyball are $29.917 \pm 5.103,26.400 \pm 2.799$ and $24.683 \pm 2.487$ respectively. Minimum and maximum values range from 20.00 to 41.00 for football; 21.00 for basketball; and 21.00 to 30.00 for volleyball players.

Table 2. Depicted comparison between football, volleyball and basketball players for anxiety.

\begin{tabular}{|llllll|}
\hline Anxiety & Sum of Squares & Df & Mean Square & $\boldsymbol{F}$ & Sig. \\
\hline Between Groups & 854.033 & 2 & 427.017 & & \\
\cline { 1 - 4 } Within Groups & 2363.967 & 177 & 13.356 & .073 & .000 \\
\hline Total & 3218.000 & 179 & & \\
\hline
\end{tabular}

$\left(\right.$ Note $=*$ Significant at 0.05 level. Tab $\left.\mathrm{F}_{0.05}(2,17)=2.10\right)$.

From table 2, it is evident that the F value, 31.97 is significant at 0.05 level with 2 and 17 degrees of freedom. The value also confirms that there is significant difference between football, volleyball, and basketball players in relation to anxiety. 


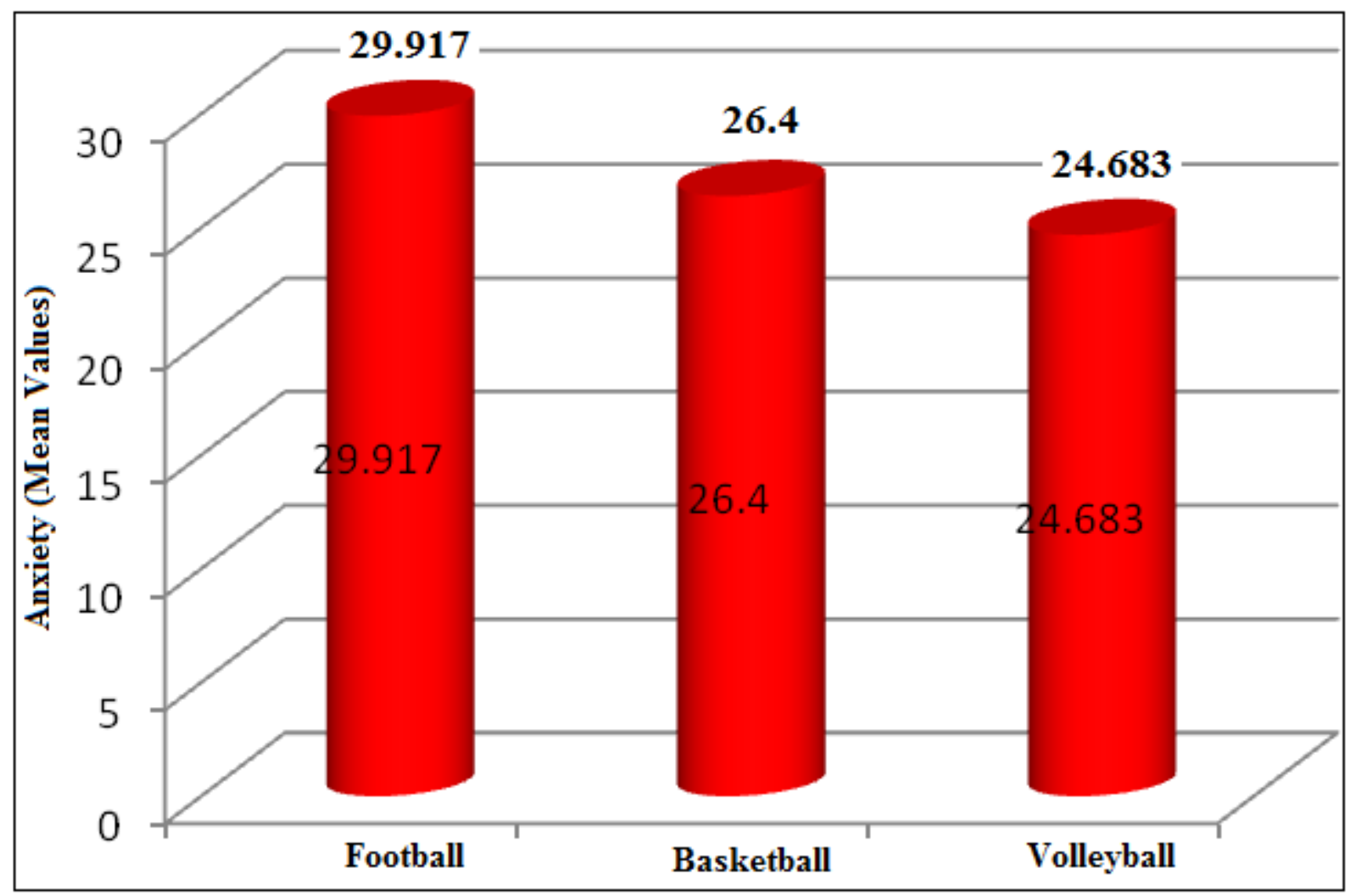

Figure 1. Comparison of anxiety mean values for football, basketball and volleyball players.

Table 3. Upper and lower bound indices for the three ballgame components after LSD POST HOC Test.

\begin{tabular}{|c|c|c|c|c|c|c|}
\hline \multirow[t]{2}{*}{ (I) Sports } & \multirow[t]{2}{*}{ (J) Sports } & \multirow{2}{*}{$\begin{array}{l}\text { Mean } \\
\text { Difference } \\
(I-J)\end{array}$} & \multirow{2}{*}{$\begin{array}{l}\text { Std. } \\
\text { Error }\end{array}$} & \multirow[t]{2}{*}{ Significance } & \multicolumn{2}{|c|}{ 95\% Confidence Interval } \\
\hline & & & & & $\begin{array}{l}\text { Lower } \\
\text { Bound }\end{array}$ & $\begin{array}{l}\text { Upper } \\
\text { Bound }\end{array}$ \\
\hline \multirow[t]{2}{*}{ Football } & Basketball & $3.51667^{*}$ & .66723 & .000 & 2.1999 & 4.8334 \\
\hline & Volleyball & $5.23333^{*}$ & .66723 & .000 & 3.9166 & 6.5501 \\
\hline \multirow[t]{2}{*}{ Basketball } & Football & $-3.51667^{*}$ & .66723 & .000 & -4.8334 & -2.1999 \\
\hline & Volleyball & $1.71667^{*}$ & .66723 & .011 & .3999 & 3.0334 \\
\hline \multirow[t]{2}{*}{ Volleyball } & Football & $-5.23333^{*}$ & .66723 & .000 & -6.5501 & -3.9166 \\
\hline & Basketball & $-1.71667^{*}$ & .66723 & .011 & -3.0334 & -.3999 \\
\hline
\end{tabular}

(Note $=*$. The mean difference is significant at 0.05 level).

Table 3 is depicting that how the scores for the components in upper and lower bound for sport anxiety levels of ratifications were determined. This allowed seeing the elements that went into the overall performance scores and enables to identify anxiety levels among the three ball games. Subsequently among the three sub-sections presented as lower and upper bound rankings the 
indices for football game was among the highest and significant at 0.05. This explains the delivery of some intervention programs to deal and cater the influence of anxiety on football performance on games ahead.

\section{DISCUSSION}

The results indicate that there is significant variation in terms of anxiety among football, volleyball and basketball student players participated in National Ethiopian Universities Sports Competitions (NEUSC) held in Haromia University during 2013-14. Though, the mean and standard deviation for basketball and volleyball were in the normal range, for football it was far beyond the normal. This implies that football game unlike the other two is more demanding. In this regard Elizabeth's study in 2012 revealed a similar mean value for football players and the values were beyond the normal range after their state level of anxiety was measured. The findings of this study is also comparable with the findings of Hardy et al. (1998) which were based on the positive linear correlation between cognitive anxiety and performance among the football players.

As the results of the present study also confirmed that the anxiety level is highest for football game compared to others may be due to its popularity, glamour and excitement in Ethiopia. It may be one of the reasons for the high increase in anxiety level among football players unlike to the volleyball and basketball players before competition (Martens, 2011). This result underscores that immense importance to the anxiety level of players, including couches and trainers before tournaments have to be given due attention for its effective control. This is because the player's performance is negatively affected if anxiety level of such actors in the game or competition is left unchecked or measured in completion sessions (Kerr, 2009; Belly, 1980).

Similar study conducted in India by Monaj (2008) also indicated the same. The study was based on the induced stress on the heart rate of players before the game and physical work load and with no sign of compensation occurring during the entire period of ergometric testing. Effect of anxiety on performance was under control. Present findings showed a significant increase in selfreported state anxiety under the stress condition in both the laboratory and field setting (Kornspan, 2007). At the same time, the mean physical performance, measured as physiological performance parameters (maximum oxygen intake, physical work capacity) or as running performance, significantly deteriorated under stress. For both laboratory situations and for the 
practice situation as well, no significant relationships, neither linear nor nonlinear, were detected. In the competition situation, however, an inverted-U relationship was found in the low traitanxious subgroup.

In a similar study findings prior research by Best (1998) has indicated that the relationship between somatic anxiety and performance is curvilinear (i.e., as anxiety increases, performance increases to a point then begins to decrease as anxiety continues to increase). However, prior research has also indicated that the relationship between cognitive anxiety and performance is negatively linear (i.e., as anxiety increases, performance decreases). As a matter of fact, the results of the present study are contrary to that of Best (1998). However, it should be noted that anxiety is considered as emotion evoking or a factors that emanate from both internal and external factors (environment) that imposes players when they are in a tournament in that stressors from biological (somatic) and/or those related to cognitive process as well have to be given due emphasis in which the principal investigator of the present study proposes to address it through clinical intervention before and after of any competition involving football game for that matter. Besides, other researches should also look into the cognitive process and anxiety for possible relationship in their further research on this aspect only to fill the gap.

It is vivid that as manifestations of the results of the current study the football players in particular should also be encouraged and motivated for maintaining their anxiety level to the average for optimum performance. In this regard, studies conducted in different parts of the world, Europe (Kerr, 2011) Latin America (Graham and Hardy, 2008) and Oceania (Martens et al., 1995) also indicate similar results. At the same time, they emphasized the importance of maintaining anxiety level of football players to the average level if not minimum.

As a matter of fact, football competitors should not only be bothered about success/losing a game at any cost rather on how they prepared and the tactic and techniques they employ against the opponent team. This may require counseling. From such counseling program, mentoring by the concerned couches or trainers should be organized for the players to cope up with the effects of anxiety before and after the competitions so as to mitigate the adverse effects of anxiety level before going beyond control at times when teams encounter or consecutive competitions.

Present study also suggests that anxiety as a factor in sport performance and how to control and mediate it attracted the attention of many football couches, managers and trainers actually under scoring. As it is a complex phenomenon, it deserves to be researched in its own situational 
analysis rather than to assume the relationships based on previous theories per se (Reilly and Williams, 2003).

\section{CONCLUSION}

Anxiety as one of the parameters was studied on student players playing football, volleyball and basketball games during National Ethiopian Universities Sports Competitions (NEUSC) held in Haromia University in 2013-14.

Based on the understanding after discussions with the experts together with the findings of the present study following conclusions are drawn.

It was found out that anxiety level in football players was more as compared to basketball and volleyball players.

Football game being highly popular and glamorous in Ethiopia may be one of the reasons for the increased anxiety levels among its players.

\section{Recommendations}

Psychological/physical training should be included in the training programs of such players so as to cope up with over anxiety before competition period.

Sufficient number of mentors is also needed to be in the side of each player for helping them to cope with the psychological distress that they face before or in the eve of competition periods.

Coaches and trainers should also take sport psychology training to help their players to mitigate the anxiety level that arise before the completion takes place.

\section{ACKNOWLEDGEMENTS}

The investigator is grateful for those participants who were involved in the present study for their immense contribution in providing the needed data .Besides, the different stakeholders who were in my side by the time of the research project. Thank you all.

\section{REFERENCE}

Belly, K.S. 1980. The effects of Anxiety of shooting proficiency among college women basket ball players. Completed Research in Health. Physical Education and Recreation, 22:133134. 
Best, D. 1998. Relaxation, Visualization - A mental image of success. Track Field Coaches Review, 72(1): 8-9.

Elizabeth, Q. 2012. Overcoming performance anxiety. Accessed, February 8: 2012. http//www. Healthlink.mow.edu/article/1031002350.htm. Retreived April 11. 2010.

Graham, J \& Hardy, L. 2008. Anxiety and Performance in Sport. John Wiley and Sons, New York, New York, pp.459-482.

Grange, P \& Kerr, J. H. 2010. Physical aggression in Australian football: A qualitative study of elite athletes. Psychology of Sport and Exercise, 11(1):36-43.

Hardy K., Basset. D.R \& Turrer, M.J. 1998. Is the breadth of individual ranges of optimal anxiety (IZOF) equal for all sport games? Tyler and Francis Group Publications.

Kerr, J. 2011. Motivation and emotion in sport: Reversal theory. East Sussex, UK: Psychology Press Ltd., pp.17-36.

Kornspan, A.S. 2007. The early years of sport psychology: The work and influence of Pierre de Couberin. Journal of Sport Behavior, 30(1): 77-93.

Lazarus, R. 2009. Thought and cognition: The interacts of anxiety. Sage Publishing. New York.

Layel, C.D. 2007. Stress, emotion, and performance in elite slalom canoeists. The Sport Psychologist, 10: 1736.

Maibam C. S \& Nongdren, R. K. 2015. Comparative Study on Anxiety Level Between Boys and Girls Football Players. Int. J. Research-Granthaalayah, 3(9):11-22.

Martens, R., Vealey R.S \& Burton, D. 2011. Competitive anxiety in sport. Human Kinetics Publishers, Champaign, Illinois, pp. 114-136.

Monaj, S. 2008. The arousal-athletic performance relationship. In: Horn, T.S (Ed), Advances in Sport Psychology, $3^{\text {rd }}$ edition, ISBN: 13:978-0-7360-5735-6, Human Kinetics Publishers, pp. 119-141.

Najmuddin, K \& Shahnawaz, K. 2014. Comparative Study of Sports Competitive Anxiety and Sports Achievement Motivation between Basketball Players and All India Intervarsity Running Events Athletes. Review of progress, 1(49): PP. 341-373.

Rainer, M. 1990. The arousal performance relationship revisited. Research Quarterly for Exercise and Sport, 51: 7790.

Ratnesh, S \& Inder, K. 2016. A comparative study on pre-competition anxiety between male Education. Sports and Health, 3(2): 263-265. 
Reilly, T \& William, A. 2003. Science and Soccer. Tyler and Francis Group, New York, Rutledge, pp. 39-52.

Singh D., Kaur, S \& Dureja, S. 2012. Emotional maturity differentials among university students. Journal of Physical Education and Sports Management, 3(3):41-45.

Suman, G \& Kuntal, T. 2014. A Comparative Study on Resting Pulse Rate and Anxiety Profile among Different Ball Games Players. Sport science, 4(11): 67-91. 